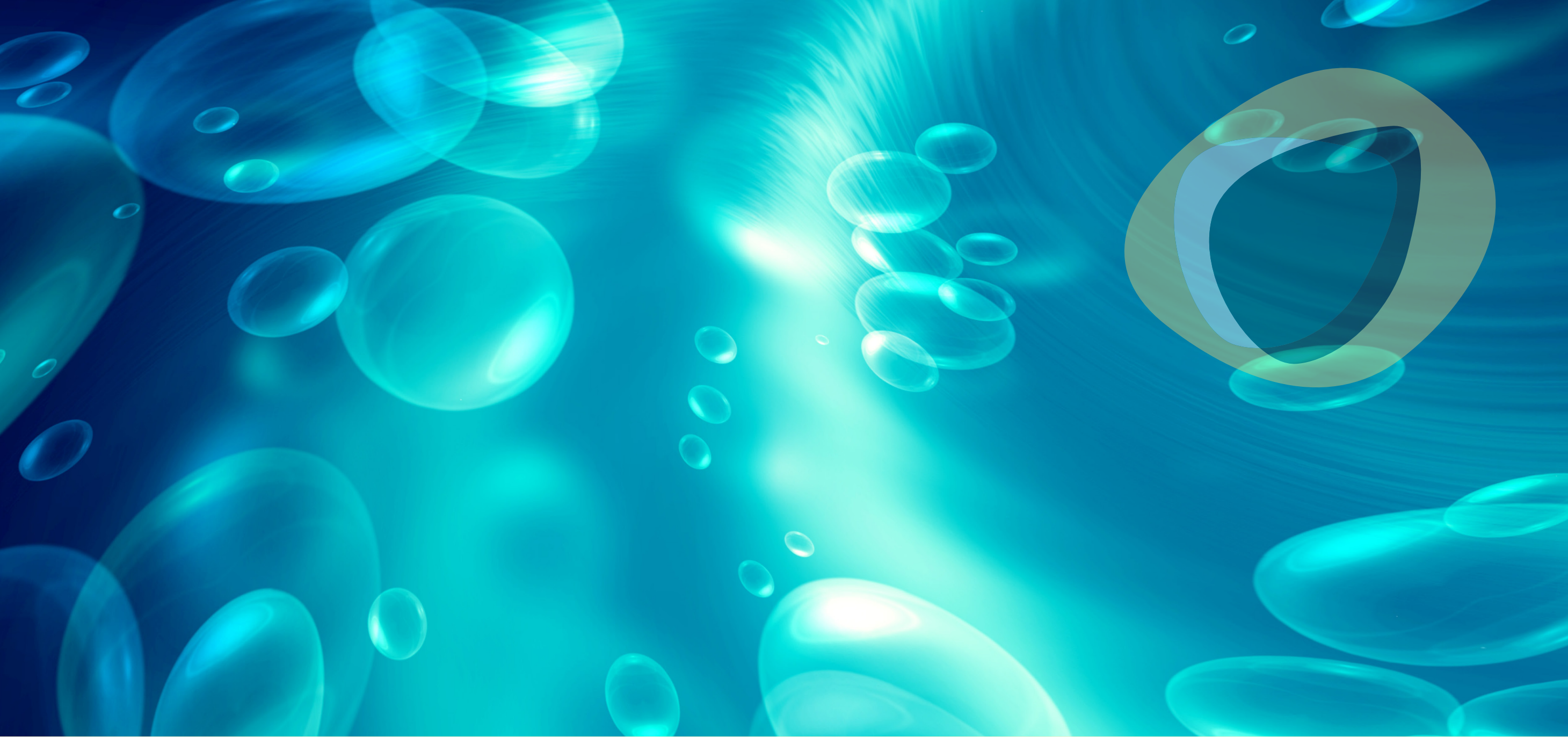

\title{
The impacts of cluster policy in Denmark
}

- An impact study on behaviour and economical effects of Innovation Network Denmark 


\section{Publisher:}

Danish Agency for Science, Technology and Innovation

This publication is available to download from the website of the

Danish Agency for Science, Technology and Innovation at

hittp://en.fi.dk/publications

ISBN (web): 978-87-92776-10-5 


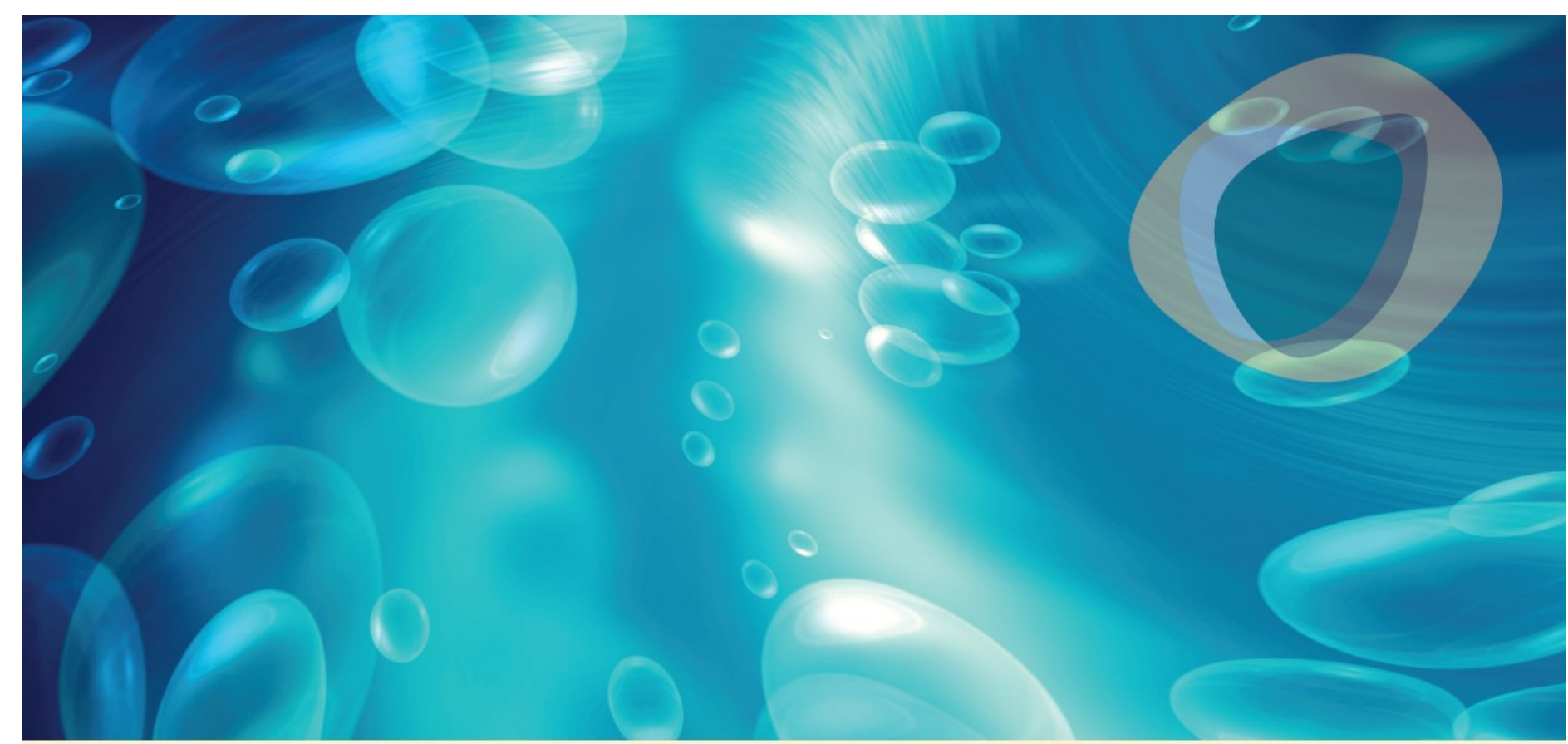

The impacts of cluster policy in Denmark

- An impact study on behaviour and economical effects of Innovation Network Denmark

\section{(it)}

Danish Agency for Science

Technology and Innovation

Ministry of Science

18/2011 in the series of Innovation: Analysis and Evaluation 


\section{Content}

Summary \& conclusions....................................................................... 4

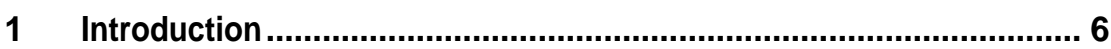

2 Innovation Networks................................................................. 7

3 Descriptive statistics.....................................................................13

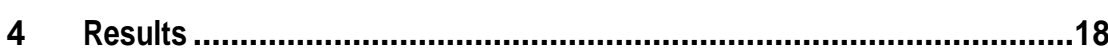

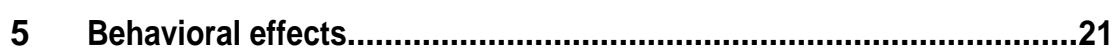

6 Possible economic impacts ...............................................................27

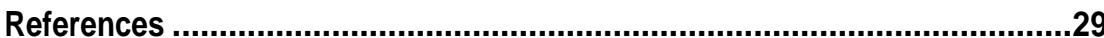

Appendix 1: Impact study methodology ...................................................30

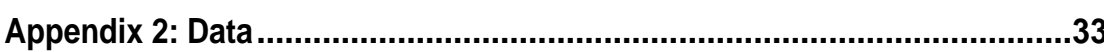

Appendix 3: The Danish Innovation Network .........................................35 


\section{Summary \& conclusions}

This is the results of the first quantitative impact assessment of innovation networks. The analysis has been conducted by DAMVAD for The Danish Agency for Science, Technology and Innovation.

The impact assessment is based on longitudinal data from 2002 to 2008 and is based the newest econometric methodologies in terms of setting up controls groups and calculating effects. Hence the control groups are established using econometric methodologies, where each of the participating companies are matched with 10 "twinning" companies. A twin company is a company with similar characteristics to participants, but with the difference, that it did not participate in the innovation networks.

By doing so we use the same approach that is well known from medical research, in which a group of test people are treated with some medication and another group is treated with placebo. Here the treats are the companies who participate in the innovation networks. Establishing a treatment and control group allows for testing the effects of given one of the groups the medicine, i.e. participating in the innovation network, and compare them to the control group, that does not receive the medicine. This creates a counterfactual situation allowing analysis of what would have been the situation without the innovation networks.

\section{Innovation networks increases the companies ability to innovate and collaborate on $R \& D$}

The impact assessment covers 1,225 participating companies in innovation networks. The results show that:
Participation increases the probability to innovate by more that 4,5 times year 1 after participation. Companies participating in different innovation networks have an increased probability of being innovative with the effects on innovation showing from the first year of participation. The probability of being innovative is 4.5 times higher for innovation network participating companies in innovation networks compared to a control group composite of other similar companies not participating in networks. This means that for every time 10 companies in the control group turns innovative 45 participating companies in innovation network will turn innovative. Among the participating companies in innovation networks we can identify 102 companies that become innovative of a treated population of 1,225 participating companies in innovation networks - an increase of 8.3 percent. On the contrary for every 1,225 participating company in the control group 22 companies turn innovative - an increase of 1.7 percent. It is a

difference of 6.5 percentage points. It is worth mentioning that a lot of these companies in both groups already are innovative. The figures above thus relates to numbers of new innovative companies adding to the number of companies already innovative.

Increasing the number of innovative companies potentially has an economical impact. The most comprehensive Danish study of private return on investment in R\&D and innovation has proven a significant return on investments in innovation of 30 percent ${ }^{1}$. Thus an increased ability to be innovative and increased probability to be innovative is expected to have a significant economical impact on the participating companies in innovation networks.

Participation increases the probability of R\&D collaboration by 4 times year 1 after participation. Innovation networks assists companies in entering joint $R \& D$ and innovation projects by providing

${ }^{1}$ The Danish Agency for Science, Technology and Innovation, 2010 
the companies with the competencies required for this complex task (and which SMEs, in particular, do not possess prior to participating). Additionally, innovation networks provide a platform within which participating companies in innovation networks identify potential collaboration partners. Already within the first year of participation, the probability of entering $R \& D$ collaboration increases by 95 percent, and thus almost doubles their probability of entering $R \& D$

collaboration. Thus every time a company in the control group composited by other similar companies not participating in innovation networks enters R\&D collaboration, two new participating companies in innovation networks enters R\&D collaboration.

The year after participating in an innovation network, the probability of entering $R \& D$ collaboration is almost 300 percent higher than other similar companies not participating in networks. In other words Participating companies in innovation networks increase their probability of entering R\&D collaboration by four times.

Another study has analyzed the impact of entering R\&D collaboration ${ }^{2}$. The study shows that companies, who are entering $R \& D$ collaboration, have significant higher growth rates in productivity compared to other similar and high productive companies. Entering R\&D collaboration increases productivity with an average of 9 percent a year over a 9 years' time period. Thus, increased $R \& D$ collaboration is expected to have a significant economical impact on the participating companies in innovation networks.

The results indicate a possible economical impact of company participation in innovation networks. One cannot expect the economical impact to show within the first few years after participation. The economical impact will not show before the increased ability to innovate and the effects from R\&D collaboration materialise in terms of new products or efficiency in the production

${ }^{2}$ The Danish Agency for Science, Technology and Innovation, 2011 process. This will in turn either increase revenue or reduce production cost, which in turn both will result in improved bottom line.

The data available does not have the longitude and time span that will enable us to carry out extensive and comprehensive studies of the economical impact. This will be possible within the following years as the time span will increase and thus enable more in dept studies of the economical impacts of company participation in innovation networks.

\section{Setting innovation networks apart}

Innovation networks are a result of a wish to boost the innovation efforts of Danish companies. Innovation networks have a particular role to play when it comes to helping small and medium-sized enterprises (SMEs) access the innovation system. They do that by providing a platform within a specific technical or professional area where companies, universities, research institutions and other relevant players can meet to exchange ideas, knowledge and launching new projects.

Thus, contrary to other R\&D and innovation programmes, the innovation networks specifically focus on inexperienced users of the knowledge system. As an innovation program, the innovation networks are based upon an informal approach. Its main function is to prepare participating companies in innovation networks to take part in and benefit from the knowledge system by increasing the innovation level, enable $R \& D$ collaboration and participation in other R\&D and innovation programmes.

In order to meet these ambitions, the scope of activities in the innovation networks is very broad and includes activities ranging from informal meetings to collaborative innovation projects. The set of activities that comprise the innovation networks also have a broader range compared to that of other innovation programs with a more narrow and focused angle, i.e. innovation consortia and others. 


\section{Introduction}

This report has been prepared by DAMVAD. It presents an analysis of the behavioural and economical impact of the Danish Innovation policy programme of Innovation Network ("Innovationsnetværk"). The behavioural impact focuses on increased ability to innovate, increase in $R \& D$ collaboration and a better use of the innovation system in Denmark. A change in the behavior is expected to lead to economical impact for the participating companies in innovation networks.

Innovation networks aims at Danish companies and knowledge institutions that are active in specific defined areas or clusters. These clusters are assembled in individual networks. Thus, firms in each network have in common that they operate with the same discipline. Although companies have the same technical focal point their motivation to engage in innovation networks have a divergent nature. Among other things motivation depend on the company's knowledge level prior to participating in the networks. This impact assessment tries to incorporate the diversity in the way controls groups are defined.

The purpose of this study is to show company effects of participation in innovation network. The participating companies in innovation networks have very diverse prerequisite related to their experience with the knowledge system. Some are novices and lack experience in innovation, R\&D collaboration and participation in the Danish system for public research and innovation promotion system, while others are experts in the knowledge system.

This also set up demands on how to design the impact assessment. Most of the participating companies in innovation networks are novices in the knowledge system. This in turn means that the main focus will be on behavior impacts as these are a prerequisite for increased innovation and R\&D, which later will lead to an economical impact.

In order to conduct a solid impact assessment the analysis identifies a control group of companies that does not participate in innovation networks. The identification builds upon propensity score matching procedures in order to identify control companies that are as identical as possible to the participating companies in innovation networks. The control group is identified based upon firm specific information regarding sector, firm size, and educational level among employees, previous performance and $R \& D$ activities.

This report is divided into 5 central chapters:

Chapter 2 describes the goals of the innovation networks, as a policy instrument and the expected effects that companies will experience from participating in the innovation networks. This is done with the purpose to set the stage for the impact assessment that follows later on in the report.

Chapter 3 gives a brief view of the participating companies in the Innovation Network program.

Chapter 4 describes how the different impacts are measured.

Chapter 5 analyses the impact of innovation network on participating companies in innovation networks in terms of behavioural impact in terms of increased ability to innovate, increased probability to enter $R \& D$ collaboration and change in use of other $R \& D$ and innovation programmes, and

Finally chapter 6 put the results of the impact assessment into perspective. 


\section{Innovation Networks}

This chapter describes the goals of the innovation networks as a policy instrument and the expected effects that companies will experience from participating in the innovation networks. This is done in order to set the stage for the impact assessment later in the report.

Innovation networks are the result of a wish to boost the innovation effort of Danish companies. The main focus of the innovation networks is to help small and medium-sized enterprises (SMEs) gain access to the innovation system. The innovation network provides a platform within a specific technical or professional area where companies, universities, research institutions and other relevant players can meet and exchange ideas and knowledge and launch shared projects. The innovation networks thus build a bridge between Danish companies and universities and other research institutions and the large accumulation of knowledge that happens there.

As the innovation networks dissemination their knowledge to participating companies in the network, the companies gradually experience a stepping upwards on the "knowledge ladder" ${ }^{3}$. The companies knowledge progress is presented in Figure 2.1 which illustrates the relation between intensity of research and development activities and economic growth.

\footnotetext{
${ }^{3}$ The concept of "the knowledge ladder" is developed based on two reports from the Danish Agency for Science and Innovation. The reports document empirical effects that companies experience from investing in $R \& D$ and innovation, and from participating in R\&D collaborations with public knowledge institutions.
}

Figure 2.1: Expected relation between R\&D intensity and productivity Roductivity per
employee

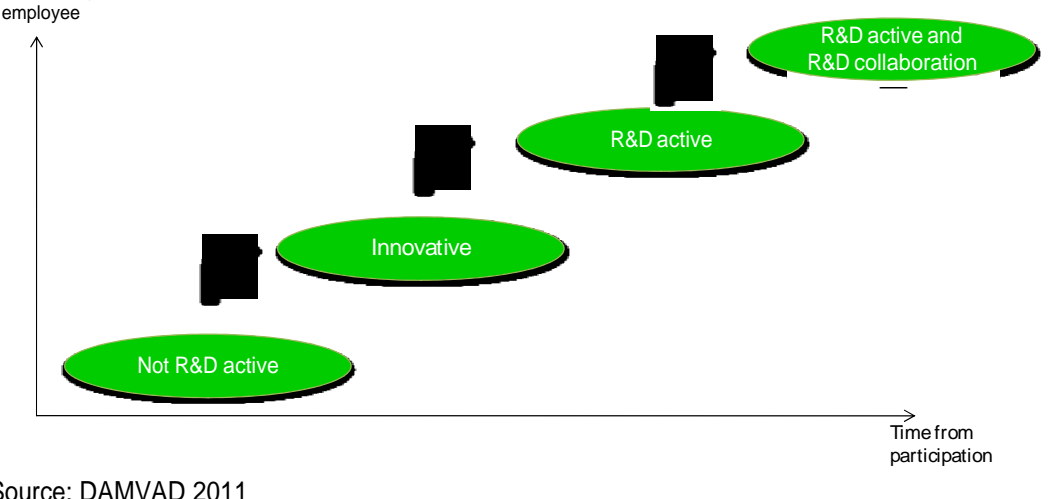

Source: DAMVAD 2011

The figure thus demonstrates how companies that were at the bottom of the ladder prior to joining the innovation network may climb up the ladder once they absorb knowledge from the network and increase their innovation and R\&D competencies. Hence, the figure is dynamic in the sense that companies at various stages may progress even further following their participation in the network activities.

Accordingly, the innovation networks will include different sets of activities that contribute to companies' progress on the knowledge ladder which are also adjusted to the companies' existing level of R\&D intensity. The advanced players will be drawn to particular activities, such as how to establish R\&D collaboration, whereas the more inexperienced players will be attracted to other activities that may help them advance their innovation competencies.

Hence, the aim of the innovation network is to provide a platform that will add value to the participating companies in innovation networks. The emphasis is on:

- Providing access to professional competencies from scientists, users, and specialised companies

- Providing room for a common generation of ideas and knowledge-sharing 
- Providing the opportunity to identify collaboration partners and to launch projects

- Providing the opportunity to strengthen and develop relations with research environments, companies, lead users, GTS etc.

- Being a stepping stone for internationalisation of companies

As the above list indicates, the scope of the innovation networks is very broad. The set of activities that make up the innovation networks also have a broader range compared to that of other innovation programs that have a more narrow and focused angle.

The scope of activities and the variety of the participating companies' innovative competencies prior to participation present specific premises for measuring the effects of participating in the innovation networks. The diversity of activities as well as company characteristics necessitates the establishing of parameters that will assist the impact assessment with large degrees of variation and with the hoped-for results taken into consideration. This will be dealt with in more depth in section 2.3.

In the following, the innovation networks as part of the knowledge system will be introduced with emphasis on what distinguishes the innovation networks from other innovation instruments. Next, the kinds of companies that participate in the innovation networks will be presented. These two dimensions will be central to the impact measurement and the expected results of participating.

\subsection{A policy instrument}

The aim of the innovation networks sets the network apart as a policy instrument compared to other innovation programs. Unlike other programs that focus on funding projects, the innovation networks provide a platform where players within a specific technical or professional area can meet. Thus the very nature of the network gives it a more informal character.

The overall difference between the innovation networks and other innovation programs such as the Strategic Research or Innovation Consortiums is highlighted in the figure below. The figure categorises the programs as to whether they are informal or formal, and whether they focus on execution of research or preparation of research.

Figure 2.2 Innovation networks placement as a policy tool

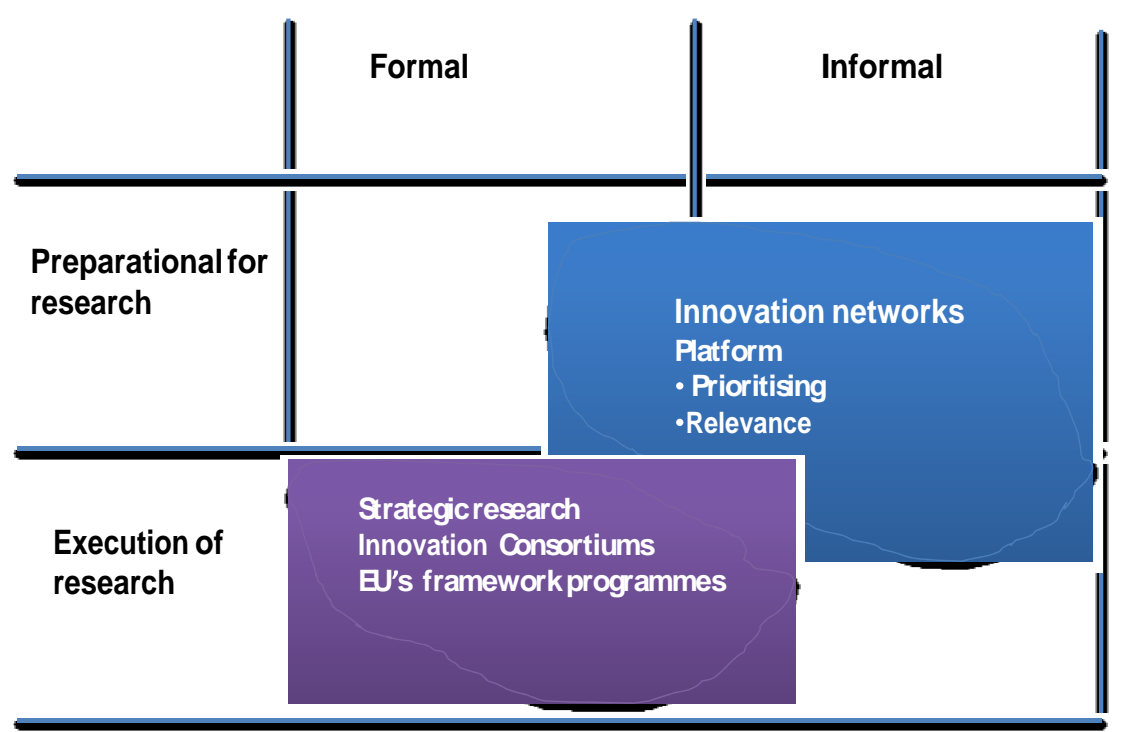

Soruce: DAMVAD 2011

As the figure indicates, the innovation networks as an innovation program are characterised as an informal policy instrument, its main function being to prepare network participating companies to participate in and benefit from the knowledge system and thus potentially participate in more formal policy instruments later. This type of program is contrasted with programs that provide specific project support and thus focus on the execution of research, giving the 
activities a more formal character, e.g. Innovation Consortiums or EU's Framework Programs.

The figure also illustrates how the innovation network supply a platform that should focus on assisting companies in prioritising research through shared development of strategies and execution of plans and by bringing participating companies in innovation networks together in order to ensure a critical mass in relation to projects.

Accordingly, research relevance is a focal point in order to make the needs of companies a more direct part of the research conducted at universities. Secondly it is also a point that a broader scopes how the needs of companies become a part of research and innovation programs. As knowledge-sharing and the dissemination of knowledge are central activities in the innovation network, the participating companies in innovation networks will contribute to the prioritization of both public and private research.

As the innovation network is to work as a bridging element for companies on the verge of unfolding their innovation potential by providing connections to other companies, universities, and research institutions in the networks, the innovation network thus potentially fills a gap in the innovation system. An additional feature of this characteristic is its ability to reach a broad range of companies that covers both very experienced players in the knowledge system as well as more inexperienced companies.

The innovation networks attract both experienced as well as inexperienced players in the knowledge system. This provides opportunities for the inexperienced players who are not familiar with the system and as such will gain practical knowledge about the knowledge system from the experienced players. Contrary it also set requirements for the activities in the networks that need to be targeted at different levels of innovation capacity and overall experience. As the preparation part of the innovation networks is distinct, the focus of the majority of activities in the network supports this dimension. However, this part is also strengthened by the existence of the more advanced companies.
The different types of companies will be elaborated below.

\subsection{Company participation on different levels}

The innovation networks reach out to different kinds of companies because of the diversity of activities in the networks. The various activities in the innovation networks also illustrate that companies participate with differing intensity and differing purposes.

It is therefore useful to provide a generic characterization of the different types of companies participating in the networks. In particular, the categorisation of companies depends on the existing level of innovation capacity, i.e. their existing R\&D expertise and their experience with the innovation system prior to participating in the network.

Inexperienced players in the knowledge system: Companies belonging to this category demonstrate a low degree of innovation capacity prior to joining the network. Their motivation for participating is focused on getting to know the central players and building relations with these players in order to get access to knowledge and competences that the company itself does not possess. The main activities that these companies participate in when they initially join the network are thus informational activities such as meetings and conferences.

New players in the knowledge system: Companies belonging to this group have some experience with the knowledge system. Their main motivation is to use the network to make more progress with their innovation attempts. A need of these companies is to get access to knowledge resources that the company does not already possess and thus the targeted activities are match-making, idea generation, counseling, and knowledge exchanges.

Advanced players in the knowledge system: This group of companies have a significant experience in operating in the knowledge system. 
Their main motivation for participating in the innovation networks is thus to use their existing knowledge combined with new knowledge for targeting new projects. Their main activities are the pre-projects that are offered as a testing platform for potentially larger projects.

Experts in the knowledge system: These companies are the experienced players in the knowledge system. They participate in innovation networks as part of their overall palette of innovation programs. These companies are also motivated by an interest in gaining access to knowledge and competencies. Their main activity is participation in innovation and R\&D projects with other key stakeholders from the network including international R\&D players.

\subsection{Effects of participation}

The innovation networks contribute to companies' development and innovation efforts in different ways. Consequently, there will be different effects of the companies participation in the innovation networks. The different effects are related to the companies' existing competencies, previous experiences of the knowledge system and involvement in innovation and research programs as well as formal joint knowledge collaboration attempts.

The different effects are presented in Figure 2.4. This figure illustrates how the effects of the innovation network depend on the type of network participant using it. The primary effect for inexperienced participating companies in innovation networks is different from the experienced network participant. Companies that participate in the network over a long period will gradually experience the strengthening of their competencies and benefit accordingly from the network and learning externalities provided through the network participation. The figure below shows how companies in theory move upwards in the knowledge system after participating in innovation networks.
Figure 2.3: Change in level within the knowledge system from participation in innovation network

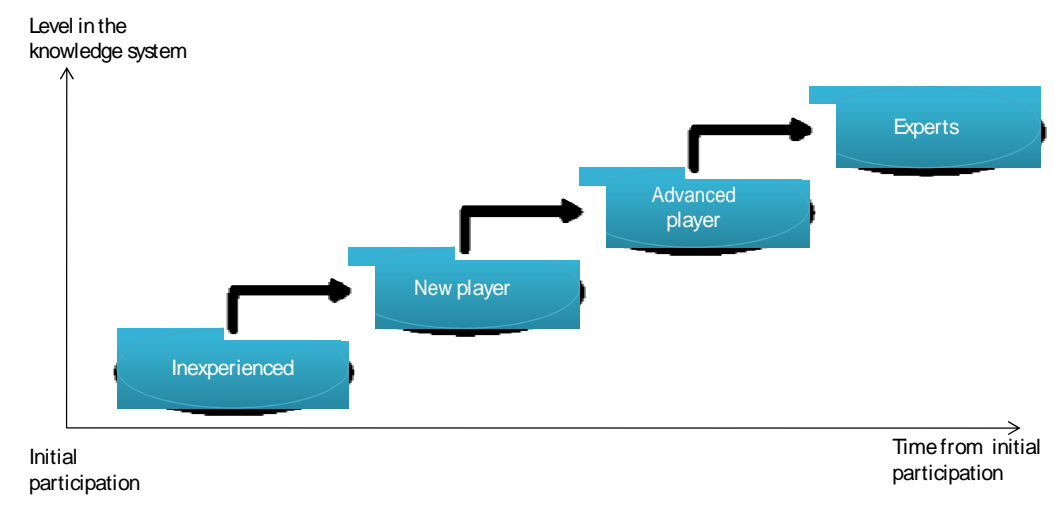

Source: DAMVAD 2011

In the short run, participation in the innovation networks will be related to behavioral effects such as changes in the characteristics of the company's R\&D activities. An example could be a company that due to participation in the innovation network increases their investments in $R \& D$, or pursues further innovation activities.

In the long run, the innovation networks will enable the companies to participate in knowledge collaboration and interaction. Thus, it is in the long term perspective that economic effects associated with participating in the innovation networks will be visible. An example of this kind of economic effect are increases in the company's productivity or increase in exports.

Companies that participate in innovation projects through collaboration with other companies and knowledge institutions facilitated by their participation in the innovation network are expected to experience economic effects sooner than companies that have only participated in meetings and workshops, regardless of the duration of their network membership. 
Figure 2.4: Effects of participation in innovation network

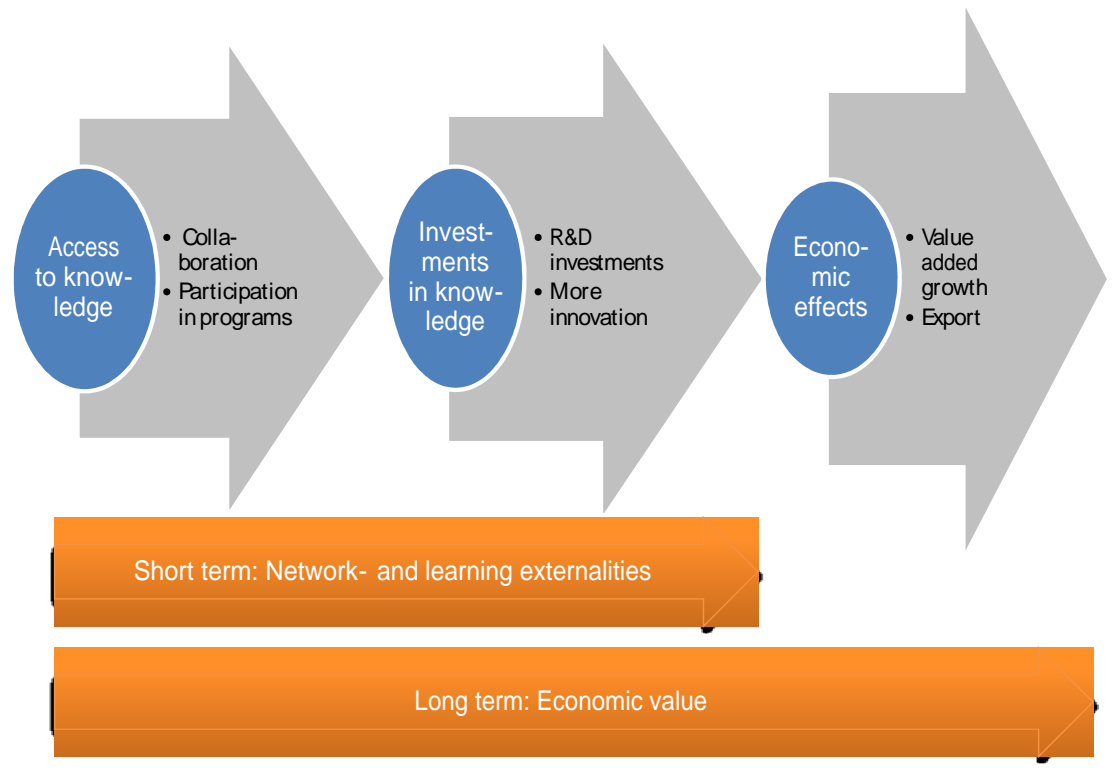

Source: DAMVAD 2011

\section{Box 2.1 What are the objectives of the innovation networks}

The main objectives of the innovation networks are:

- To strengthen public-private collaboration and knowledge transfer between public universities and private companies on research and innovation.

- To strengthen innovation and research in Danish Companies and thus promote knowledge based growth in business and industry.

Below is a brief overview of the 22 existing innovation networks and the identified participating companies in innovation networks. A more comprehensive, but still brief description of each innovation network can be found in appendix 3.

\subsection{The Danish Innovation Network}

This gives a brief presentation of the Danish innovation networks. In appendix 3 there is a more thorough presentation of each network. The text box below presents the more formal objectives of the innovation networks: 


\section{Table 2.1. Overview of innovation network}

\begin{tabular}{|l|}
\hline Network \\
\hline AluCluster - Knowledge and technology centre for aluminium \\
\hline Animation HUB \\
\hline Biopeople - Innovation Network for Biotech \\
\hline Innovation Network for Biomass \\
\hline Danish Sound Technology Network \\
\hline FoodNetwork - Fødevaresektorens Innovationsnetværk \\
\hline Infinit - The Danish ICT Innovation network \\
\hline InnoBYG - Innovation Network for Energy efficient and Sustainable construction \\
\hline Innonet Lifestyle - Interior \& Clothing \\
\hline The Innovation network for Market, Communication and Consumption \\
\hline The Innovation network for Environmental Technology \\
\hline Offshore Center Denmark \\
\hline Innovation Network for Danish Lighting \\
\hline Plastic and Polymer Network \\
\hline InViO - Innovation network for knowledge-based experience economy \\
\hline No Age - innovative solutions for elderly people \\
\hline RoboCluster \\
\hline Service Platform - Service Cluster Denmark \\
\hline The Transport Innovation Network - TINV \\
\hline UNIC - Use of New technologies in Innovative solutions for Chronic patients \\
\hline Water in Urban Areas \\
\hline VE-NET \\
\hline Source: DAMVAD 2011 based on participation list for innovation networks \\
\hline
\end{tabular}




\section{Descriptive statistics}

The following is aiming at giving a descriptive status on the participating companies of the Innovation Network program. Two of the key performance indicators for this program are the focus on regional distribution and inclusion of small companies.

In order to provide further information on the participating companies in innovation networks, data is merged with other statistics. Merging Statistic on Research, Development and Innovation and General enterprise statistics leads to a further reduction of companies. The final number of participating companies in innovation networks is 3,031.

The total number of companies participating in current innovation networks will not correspond with the numbers of participating companies in innovation networks in the impact analysis. The impact analysis cover participating companies in innovation networks in the time span 2003 to 2008. The innovation networks are rather dynamic and their scope changes from year to year, some stays the same, some are closed down, new ones appear and some are merged.

The study covers 3,031 participating companies in the Danish Innovation policy program of Innovation Networks. The majority of participating companies in innovation networks come from the manufacturing, business, commerce and transportation sectors. These industries account for 67 percent of the participating companies in innovation networks. Table 3.1 shows the distribution of participating companies in innovation networks by industry.
Table 3.1. Participating companies in innovation networks by industry

\begin{tabular}{|lcr|r|}
\hline \multicolumn{1}{|c|}{ Industry } & $\begin{array}{c}\text { Number of } \\
\text { participating } \\
\text { companies }\end{array}$ & $\begin{array}{c}\text { Fraction of } \\
\text { participating } \\
\text { companies }\end{array}$ & $\begin{array}{r}\text { Fraction of } \\
\text { total } \\
\text { companies }\end{array}$ \\
\hline Agriculture, forestry \& & 62 & $2,0 \%$ & $12,3 \%$ \\
\hline Manufacturing & 844 & $27,8 \%$ & $6,7 \%$ \\
\hline Construction & 48 & $1,6 \%$ & $11,6 \%$ \\
\hline Trade and transport ect. & 558 & $18,4 \%$ & $24,0 \%$ \\
\hline Information and & 361 & $11,9 \%$ & $3,9 \%$ \\
\hline Financial and insurance & 80 & $2,6 \%$ & $3,5 \%$ \\
\hline Real estate \& renting & 27 & $0,9 \%$ & $8,6 \%$ \\
\hline Other business services & & & \\
\hline \multicolumn{1}{|c|}{ Knowledge-based services } & 569 & $9,5 \%$ & $18,8 \%$ \\
\hline Travel agent, cleaning, ect. & 57 & $4,9 \%$ & $1,9 \%$ \\
\hline Arts, entertainment \& other & 182 & $6,0 \%$ & $6,7 \%$ \\
\hline Public administration, & 174 & $5,7 \%$ & $8,0 \%$ \\
\hline Undisclosed activity & 69 & $2,3 \%$ & $0,3 \%$ \\
\hline All & 3.031 & & \\
\hline Source: DAMVAD 2011 based & & & \\
\hline
\end{tabular}

Source: DAMVAD 2011 based on General enterprise statistics (2008) and participation list for innovation networks.

The regional distribution of participating companies in innovation networks matches the general distribution of companies. The Innovation Networks thus lives up to the aim of having a wide regional distribution of activities ${ }^{4}$. Geographically, most participating companies in innovation networks are based in the capital and central Jutland. This is most likely because the concentration of companies in general in these areas is higher than in other parts of the country. It is noteworthy that there are relatively few participating companies in innovation networks from Region Zealand. The results of table 3.2

${ }^{4}$ The aim is part of the key performance indicators as is presented in the action plan for The Danish Council for Technology and Innovation 2010 - 2013 
show that besides Region Zealand the different Danish regions are represented on a level that matches the relative distribution of companies in general.

Table 3.2. Participating companies in innovation networks by region

\begin{tabular}{|lcrr|}
\multicolumn{1}{c}{ Name of Region } & $\begin{array}{c}\text { Number of } \\
\text { participating } \\
\text { companies }\end{array}$ & $\begin{array}{c}\text { Fraction of } \\
\text { participating } \\
\text { companies }\end{array}$ & $\begin{array}{c}\text { Fractions of } \\
\text { total } \\
\text { companies }\end{array}$ \\
\hline Capital Region & 908 & $30,0 \%$ & $30,7 \%$ \\
\hline Central Denmark Region & 797 & $26,3 \%$ & $22,9 \%$ \\
\hline North Denmark Region & 498 & $16,4 \%$ & $10,7 \%$ \\
\hline Region Zealand & 175 & $5,8 \%$ & $14,6 \%$ \\
\hline Region of south Denmark & 653 & $21,5 \%$ & $21,0 \%$ \\
\hline All & 3,031 & & \\
\hline
\end{tabular}

Source: DAMVAD 2011 based on General enterprise statistics (2008) and participation list for innovation networks.

Another focus in the key performance indicators for the Innovation Networks program is a focus of including small companies. In numbers, most companies participating in innovation networks are small. But compared with the general distribution by size, large companies are over-represented among the participating companies in innovation networks. In Denmark in general, 1.5 percent of businesses have more than 50 employees. By comparison 28.4 percent of firms in the innovations programs have more than 50 employees.

Compared to other Danish programs for R\&D and innovation, the share of small companies is rather high. E.g. in the program for Strategic Research 40 percent of the participating companies have more than 250 full time equivalent employees and in Innovation Consortia the figure is 27 percent. The Innovation Network programme 11.3 percent of the participating companies in innovation networks have more than 250 full time equivalent employees.
Table 3.3. Participating companies in innovation networks by size

\begin{tabular}{|c|c|c|c|}
\hline $\begin{array}{c}\text { Company size in } \\
\text { full-time } \\
\text { equivalent }\end{array}$ & $\begin{array}{c}\text { Amount of } \\
\text { participating } \\
\text { companies }\end{array}$ & $\begin{array}{c}\text { Fraction of } \\
\text { participating } \\
\text { companies }\end{array}$ & $\begin{array}{c}\text { Fraction of } \\
\text { total } \\
\text { companies }\end{array}$ \\
\hline 0 to 19 & 1,730 & $57,1 \%$ & $96,0 \%$ \\
\hline 20 to 49 & 441 & $14,5 \%$ & $2,5 \%$ \\
\hline 50 to 99 & 270 & $8,9 \%$ & $0,8 \%$ \\
\hline $100+$ & 590 & $19,5 \%$ & $0,7 \%$ \\
\hline All & 3,031 & & \\
\hline
\end{tabular}

Source: DAMVAD 2011 based on General Enterprise Statistics (2008) and participation list for innovation networks.

Note: 346 companies have more than 250 employees. This mean that 11,3 percent of the innovation network participant have more than 250 employees.

\subsection{Innovation profile}

The following presents the level of innovative participating companies in innovation networks. Tabel 3.4 shows that 51,2 percent of the participating companies in innovation networks in 2004 are innovative. This is compared to that 42 percent of the Danish companies were innovative in 2004. 73.1 percent of the companies participating in 2007 are innovative. This is compared to that 42.8 percent of the Danish companies were innovative in 2007. 
Table 3.4. Participating companies in innovation networks Innovative

\begin{tabular}{|ccc|}
\hline $\begin{array}{c}\text { Innovative in year } \\
\text { of participation }\end{array}$ & $\begin{array}{c}\text { Fraction of } \\
\text { participating } \\
\text { companies }\end{array}$ & $\begin{array}{c}\text { Fraction of total } \\
\text { companies }\end{array}$ \\
\hline 2004 & $51.2 \%$ & $42.0 \%$ \\
\hline 2007 & $73.1 \%$ & $42.8 \%$ \\
\hline 2008 & $73.6 \%$ & $41.0 \%$ \\
\hline
\end{tabular}

Source: DAMVAD 2011 based on innovation statistics (2004, 2007 and 2008) and participation list for innovation networks.

\subsection{R\&D-profile}

68.3 per cent of the participating companies in Innovation Networks are engaged in $R \& D$ activities. Compared with the total amount of companies in Denmark, participating companies in innovation networks are more likely to be involved in $R \& D$ activities as only 35.6 percent of all Danish companies are engaged in R\&D. This is of cause due to self-selection, as the companies analysed here by definition are engaged in innovation. The question is whether the companies are active in R\&D because they participate in the Innovation Networks program, or if they were $R \& D$ active before entering the program.

Table 3.5. Participating companies in innovation networks R\&D activity

\begin{tabular}{|l|ccc|}
\hline $\begin{array}{c}\text { R\&D } \\
\text { activity }\end{array}$ & $\begin{array}{c}\text { Amount of } \\
\text { participating } \\
\text { companies }\end{array}$ & $\begin{array}{c}\text { Fraction of } \\
\text { participating } \\
\text { companies }\end{array}$ & $\begin{array}{c}\text { Fraction of total } \\
\text { companies }\end{array}$ \\
\hline No & 203 & $31.7 \%$ & $64.2 \%$ \\
\hline Yes & 438 & $68.3 \%$ & $35.8 \%$ \\
\hline All & 641 & & \\
\hline
\end{tabular}

Source: DAMVAD 2011 based on R\&D-statistics (2008) and participation list for innovation networks.
Another interesting point in the analysis will be the focus on R\&D collaboration. The participating companies of Innovation Networks are more likely to cooperate on R\&D than other companies. Around 30 per cent of participating companies in innovation networks cooperate, where only 5.4 percent of all Danish companies cooperate on R\&D. It will thus be interesting to see whether the higher share of $R \& D$ collaboration is due to participation in the Innovation Network program.

Table 3.6. R\&D-cooperation among companies in innovation networks

\begin{tabular}{|lcccc|}
\hline \multirow{2}{*}{$\begin{array}{c}\text { R\&D- } \\
\text { cooperation }\end{array}$} & $\begin{array}{c}\text { Amount of } \\
\text { participating } \\
\text { companies }\end{array}$ & & $\begin{array}{c}\text { Fraction of } \\
\text { participating } \\
\text { companies }\end{array}$ & $\begin{array}{c}\text { Fraction of total } \\
\text { companies }\end{array}$ \\
\hline No & 427 & $69.3 \%$ & $94.6 \%$ \\
\hline Yes & 189 & $30.7 \%$ & $5.4 \%$ \\
\hline All & 616 & & \\
\hline Sonnnn & & & & \\
\hline
\end{tabular}

Source: DAMVAD 2011 based on R\&D-statistics (2008) and participation list for innovation networks.

\subsection{Network participation}

As mentioned above small or middle sized are most likely to participate in Innovation Networks. The table below shows that 58.1 percent of the participating companies in innovation networks have less than 20 employees whereas 11.3 percent have more than 250 employees. 
Table 3.7. Network participation by firm size

\begin{tabular}{|l|ccccc|}
\hline Network & $\begin{array}{c}\text { Company size in full-time } \\
\text { equivalent }\end{array}$ & & \\
& 0 to 19 & 20 to 49 & 50 to 99 & $\begin{array}{c}100 \text { to } \\
249\end{array}$ & $250+$ \\
\hline All & $\mathbf{1 , 7 3 0}$ & $\mathbf{4 3 8}$ & $\mathbf{2 5 2}$ & $\mathbf{2 2 1}$ & $\mathbf{3 3 7}$ \\
\hline Share & $58.1 \%$ & $14.7 \%$ & $8.5 \%$ & $7.4 \%$ & $11.3 \%$ \\
\hline
\end{tabular}

Source: DAMVAD 2011 based on General Enterprise Statistics (2008) and participation list for innovation networks.

From the data on participating companies in innovation networks it is possible to see the different kinds of activities that each company has participated in. The different activities increase in strength and formality so that conferences and seminars are the most casual and informal activity whereas R\&D and innovation project are the most formal.

Overall, most companies participate in the informal conferences or seminars. Almost 3,000 companies have been participating in these activities, while only 419 companies have been participating in formal $R \& D$ and innovation projects. It is possible for each company to participate in five activities altogether. Table 3.7 presents the results.

Most companies participate in conferences or seminars. This is 98 percent of the participating companies in innovation networks. 14 percent are involved in innovation and R\&D projects.
Table 3.8. Network participation by activity

\begin{tabular}{|lccccccc|}
\hline Network & $\begin{array}{c}\text { Conf. or } \\
\text { Seminars }\end{array}$ & $\begin{array}{c}\text { Thematic } \\
\text { matching }\end{array}$ & & $\begin{array}{c}\text { Con- } \\
\text { sulting }\end{array}$ & $\begin{array}{c}\text { Preli- } \\
\text { minary or } \\
\text { small } \\
\text { projects }\end{array}$ & $\begin{array}{c}\text { R\&D or } \\
\text { inno. } \\
\text { projects }\end{array}$ \\
\cline { 2 - 3 } \cline { 6 - 7 } & $\mathbf{2 , 9 6 5}$ & $\mathbf{1 , 5 3 7}$ & & 592 & $\mathbf{2 4 0}$ & $\mathbf{4 1 9}$ \\
\hline Percentage & $98 \%$ & $51 \%$ & & $20 \%$ & $8 \%$ & $14 \%$ \\
\hline
\end{tabular}

Source: DAMVAD 2011 based on General Enterprise Statistics (2008) and participation list for innovation networks.

\subsection{Participation in other programs}

One of the main aims of the Innovation Networks program is to increase participation in other R\&D and Innovation programs, inviting novices to enter into the innovation system. By merging the participation list with the DAMVAD Database on Knowledge Collaboration, it is possible to see how many of the innovation network participating companies that are also participating in other programs. It is an aim of the Innovation Networks program to improve each company's ability to innovate, increase the overall investments in $R \& D$ and innovation and increase the number of joint $R \& D$ and innovation projects between companies and knowledge institutions.

Around 25 per cent of the participating companies in innovation networks have participated in a project recorded in the DAMVAD Database on Knowledge. The participation in other programmes shows that the participating companies in innovation networks also participate in other parts of the knowledge system. It is part of this analysis to see whether participation in innovation network will enhance company participation in other programmes. 
Table 3.9. Network participation by activity

\begin{tabular}{|l|c|c|c|}
\hline Network & $\begin{array}{c}\text { Participating } \\
\text { companies in } \\
\text { Innovation } \\
\text { Network }\end{array}$ & $\begin{array}{c}\text { Participating in } \\
\text { other }\end{array}$ & Share in per cent \\
All & $\mathbf{4 , 0 2 1}$ & $\mathbf{1 , 0 2 2}$ & $\mathbf{2 5 , 4}$ \\
\hline
\end{tabular}

Source: DAMVAD 2011 based on DAMVAD co and participation list for innovation networks.

Table 3.10 show companies that participate in innovation network and how they participate in other $R \& D$ and innovation programmes. Further the figures is divided into firm size. By doing so we see how many small, medium sized and large companies participating in innovation networks also participates in other programmes. It is an aim for the innovation network to help and enhance the use of other programmes, especially for small and medium sized companies. And it is in particular programmes focusing on innovation, which attracts participating companies from the innovation networks. Table 3.10 shows that the programmes "User Driven Innovaiton", "Innovation Consortia" and "Knowledge Coupons" all attract a great share of small or medium sized companies.
Table 3.10. Network participation by activity

\begin{tabular}{|c|c|c|c|}
\hline Program & $\begin{array}{l}0 \text { to } 49 \text { full } \\
\text { time } \\
\text { employees }\end{array}$ & $\begin{array}{c}50 \text { to } 249 \text { full } \\
\text { time } \\
\text { employees }\end{array}$ & $\begin{array}{l}+250 \text { full time } \\
\text { employees }\end{array}$ \\
\hline ABT fonden & $\ldots$ & $\ldots$ & $\ldots$ \\
\hline User Driven innovation & 53 & 28 & 56 \\
\hline ELFORSK & 10 & 13 & 36 \\
\hline $\begin{array}{l}\text { EU's 4. Framework } \\
\text { programme }\end{array}$ & 19 & 16 & 37 \\
\hline $\begin{array}{l}\text { EU's 5. Framework } \\
\text { programme }\end{array}$ & $\cdots$ & $\cdots$ & 22 \\
\hline $\begin{array}{l}\text { EU's 6. Framework } \\
\text { programme }\end{array}$ & 46 & 27 & 72 \\
\hline $\begin{array}{l}\text { EU's 7. Framework } \\
\text { programme }\end{array}$ & 25 & 12 & 46 \\
\hline EUDP & 29 & 12 & 41 \\
\hline Food Innovation 2007 & 13 & $\ldots$ & $\ldots$ \\
\hline $\begin{array}{l}\text { High Technology } \\
\text { Foundation }\end{array}$ & 20 & 14 & 39 \\
\hline Innovation Consortia & 54 & 61 & 109 \\
\hline Regional Programmes & 19 & 22 & 32 \\
\hline $\begin{array}{l}\text { Council for Strategic } \\
\text { Research }\end{array}$ & 20 & 17 & 53 \\
\hline Knowledge Coupon & 70 & 21 & 0 \\
\hline All & 378 & 243 & 543 \\
\hline
\end{tabular}

Source: DAMVAD 2011 based on General Enterprise Statistics (2008) and participation list for innovation networks.

Note: ... mean that the figure left out due to discretion matters.

Note: The figure of larger companies exceed figure in table 3.6. This is due to the fact that one company can participate in several programmes. 


\section{Results}

It is expected that companies will experience different effects from participating in Innovation Network. As described in Chapter 2 there are different patterns of participation. These different patterns have different aims and thus their impact should be viewed separately. It is crucial to focus on different impact measurements that focus exclusively on economic impacts, such as productivity and exports, but also changes in behaviour that in the end will imply economic growth.

This analysis focuses on two themes of the overall impact of participating in Innovation Networks:

- Behavioural effects

- Economic impacts

The time span of the individual company's participation in an Innovation Network will be of great importance as to which kinds of effects can be expected. The figure below illustrates the expected coherence between effects and the time span of participation. The figure shows how the initial phase of participation leads to potential behavioural effects, e.g. increased $R \& D$ spending or establishment of own R\&D department.

The ever growing knowledge base gained by participation, combined with behavioural changes such as increased investments in $R \& D$, will affect the economic impact of the individual company, e.g. by increased productivity, revenue or employment.
Effect of participating in an Innovation Network

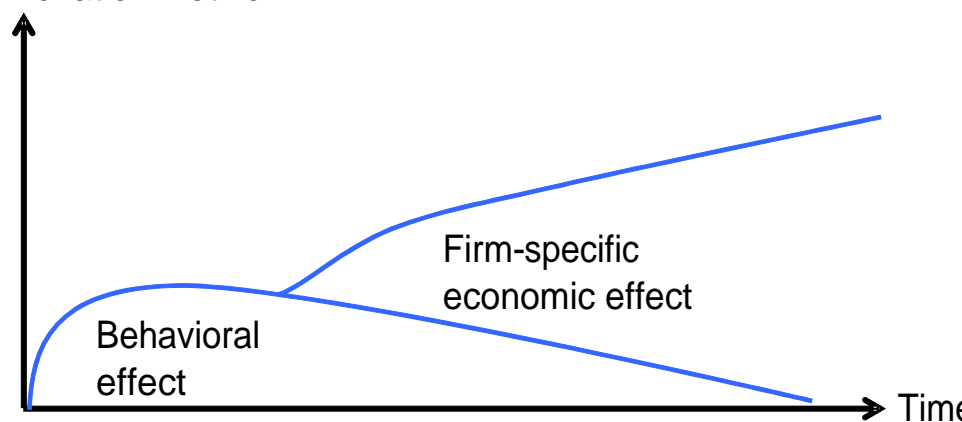

Source: DAMVAD, 2011

\subsection{What is meant by impact}

\section{Behavioral effects}

The behavioural impact of participating in an Innovation Network is measured by an increased probability of being innovative, increased probability of entering into a R\&D collaboration and by a better use of existing national and international $R \& D$ and innovation programs,.

One behavioural effect is measured by increased ability to be innovative. This is direct key performances aim with the Innovation Network program. Increased innovation is a possible driver of improved economic performance. An analysis on the return of increased investments in innovation conducted by DAMVAD and the Danish Centre for Studies in Research and Research Policy proved that investing one additional Euro in innovation yields a return of 30 cents. More innovation will thus increase the company growth. 
A second behavioural effect studied here is the level of R\&D collaboration. A recent study conducted by DAMVAD proved that a business that enters into an R\&D collaboration with universities and other knowledge institutions on average experiences a 9 percent increase in productivity a year in a 9 year period. Therefore it is important to increase R\&D collaboration, and it is also a key performance indicator for the Innovation Network program in the action plan Innovation Denmark 2010-2013.

A better use of existing national and international R\&D and innovation programs covers several of key performance indicators for the Innovation Network program. Participation in other programs will most likely increase the individual company's ability to innovate, increase investments in $R \& D$ and innovation and increase the general level of collaboration between companies, universities and other knowledge institutions. Two Danish studies have proven a relationship between, respectively, increased innovation, increased R\&D and R\&D collaboration on the one hand, and business growth in terms of increased productivity on the other. This was shown in Figure 2.1 and is known as the knowledge ladder. It is therefore highly relevant to aim for a better use of existing national and international $R \& D$ and innovation programs.

For each of the indicators our methodology focuses on causality. We match control companies so that they are similar to Innovation Network participating companies in innovation networks in the year that the latter participate in a network. The similarity is based on a range of company specific indicators and the economical performance of each company, in order to ensure the similarity between the participating companies in innovation networks and the control group.

\section{Economical effects}

The economic impact of participating in Innovation Networks is measured in terms of productivity, exports, turnover and employment. The measuring of the economic impact has been carried out from two different perspectives. First, the general effect is measured regardless of the character of participation. Secondly, the impact is estimated while the character of participation is taken into account.

For each of the two perspectives we use a matching approach to estimate the causal effect of participation in Innovation Networks. This approach matches each participant with a similar non-participant, hereby simulating a counterfactual situation.

When estimating the impact of participation, causality is a very important issue. The question is whether companies perform better as a result of participating in Innovation Networks, or whether high performance companies are more likely to join Innovation Networks. This issue is addressed first by matching the participating companies in innovation networks with non-participating but similar companies (the control group).

Secondly, the performance of the participating companies in innovation networks is compared to the performance of the control group over time. The performance of the control group is assumed to illustrate the performance paths that the participating companies in innovation networks would have followed had they not participated.

\subsubsection{Establishing control groups}

In this impact study we establish one solid control group and use it to compare the before and after behavioural activities between participating companies in innovation networks and similar nonparticipating companies. 
Companies are selected for a control group according to the matching method called "propensity score matching". This method estimates for each company the probability of participating in innovation network conditional on company specific characteristics such as industry, company size, exports, educational background of employees, previous performance, $R \& D$ activities and research collaborations. According to the estimated probability, participants are matched to similar non-participants according to nearest neighbour matching method. This is further elaborated in appendix 1.

As a result, the control groups consist of companies that are similar to participating companies in innovation networks, where the only observed difference is the fact that these companies did not participate in an innovation network.

It is important to consider the quality of the control group. This is done by testing if observations with the same propensity score have the same distribution of observable covariates independent of treatment status. In other words, it has been tested whether there are any observed systematic differences between participating companies in innovation networks and the control group consisting of the matched non-participating companies.

The economic methodology is further elaborated in appendix 1. 


\section{Behavioral effects}

The behavioral effect is not immediately transferrable to economic measures and as such economic impacts. But they can be a prerequisite to later economical impacts, e.g. increased probability to innovate or increased probability of engaging in R\&D collaboration with universities and other knowledge institutions.

The analysis of behavioral effects focus on three different types of effects from participation:

- Higher probability of being innovative

- Higher probability of R\&D collaboration.

- A better use of existing national and international R\&D and innovation programs.

\subsection{Increased ability to innovate}

Another interesting area to explore is whether participation increases the innovation ability among companies. The return on investment in innovation is 30 percent and innovative companies in general are 66 percent more productive than non-innovating companies ${ }^{5}$. Further it is one of the key performance indicators to increase innovation as a mean of the Innovation Networks.
In order to analyze whether participation in innovation networks increases the probability after we utilize a probability model that is modeling the probability of being innovative for each company. The model is in principle equal to the one used to investigate a better use of other R\&D and innovation programmes.

The results again represent a logistic model that allows for including other predictor variables that will affect the probability of being innovative. The model is build upon merging data from the participation list, the General Enterprise Statistics and Innovation Statistics in 2002, 2004, 2007 and 2008. Innovation is defined based on the Innovation Statistics and for 2002 and 2004 it includes product and process innovation whereas 2007 and 2008 also includes organizational and marketing innovation. Further the results are conditioned that companies not previously have been innovative.

\section{Increasing the level of innovation among participating companies in innovation networks}

Tabel 5.1 shows that compared to similar companies participating in Innovation Networks increases the probability of being innovative.

Already the same year as participating in an innovation network companies tend to be more innovative. Year 1 after participation the probability of being innovative is 366 percent higher for innovation network participating companies in innovation networks than other similar companies. The "not available" in the tabel indicates that there weren't enough observation on innovative companies. This will be due to the lack of innovation statistics in the years of 2005 and 2006.

${ }^{5}$ Cf. The Danish Agency for Science, Technology and Innovation, 2010, 2011 
Table 5.1: Level of innovation after participating in Innovation Networks

\begin{tabular}{|lc|}
\hline $\begin{array}{l}\text { Year after participating in } \\
\text { Innovation Networks }\end{array}$ & $\begin{array}{c}\text { Increased probability of being } \\
\text { innovative }\end{array}$ \\
\hline The same year & $0.4786^{\star *}$ \\
\hline Year 1 after participation & $3.6678^{\star \star *}$ \\
\hline Year $\mathbf{2}$ after participation & $\mathrm{N} / \mathrm{A}$ \\
\hline Year $\mathbf{3}$ after participation & $\mathrm{N} / \mathrm{A}$ \\
\hline Year $\mathbf{4}$ after participation & $4.6386^{\star * *}$ \\
\hline Year $\mathbf{5}$ after participation & $3.2029^{\star \star *}$ \\
\hline
\end{tabular}

Source: DAMVAD, 2011.

Note: The significance is marked with asterisk : ${ }^{* *}=1$ pct.-level, ${ }^{* *}=5$ pct.-level and ${ }^{*}=10$ pct.level.

N: 5,201

The results imply that every time two company in the control group turn innovative 9 companies will turn innovative in the treatment group. In the time span we can locate 102 participating companies in innovation networks turning innovative out of a population of 1,225. Contrary 22 companies out of every 1,225 companies in the control group turns innovative. This means that 8.3 percent of the participating companies in innovation networks turn innovative. In the counterfactual situation without participation in innovation networks only 1.7 percent of the companies will turn innovative. That is a significant difference of 6.5 percentage points.

\section{Interpreting the results}

The results of the impact assessment show that participation in an innovation network significantly increases the probability of being innovative. There are several possible explanations to why this is the case:

Participation implies learning externalities as we shaw in chapter 2 in figure 2.4 it is expected that participating companies in innovation networks strengthening of their competences and accordingly benefit from the learning externalities provided through the network participation. This will potentially lead to innovation.

Participant gains access to new knowledge one of the key points in the activities in the networks is "bridge builder" function where participating companies in innovation networks gain access to professional capabilities from researchers, users or other companies. This knowledge help develops ideas into new products or services and provides inputs and advice for solving problems with product development and innovation.

Participation in common idea generation as part of the knowledge transfer participating companies in innovation networks can achieve counseling and individual feedback from experts. The counseling and feedback is based on the latest knowledge within certain areas. The network can act like an expert itself or putting up the frame for a meeting between participating companies in innovation networks and other experts. 


\subsection{Increase the probability of $R \& D$ collaboration}

One of the objectives of the innovation networks is to strengthen public-private collaboration and knowledge transfer between public universities and private companies regarding research and innovation. And as such it is a key performance indicator. A recent study has proven the significant effects for companies of entering public-private collaboration ${ }^{6}$.

In order to investigate whether an innovation network is an effective instrument to stimulate knowledge sharing and interaction between companies, universities and other public knowledge institutions through increased R\&D collaboration.

$R \& D$ collaboration is defined as in the official $R \& D$ statistics and covers active participation in common projects regarding R\&D with other companies or institutions. With the different $R \& D$ statistics it is possible to see whether companies have R\&D collaboration in the years of 1999, 2001, 2003 2004, 2005, 2007 and 2008. The years 1999 and 2001 will solely be used to check that companies not previously have had $R \& D$ collaboration. The following years will be used to analyze whether the companies are entering R\&D collaboration.

\section{Increasing $R \& D$ collaboration}

Table 5.2 shows that compared to other similar companies participating in an innovation network have a higher probability of entering $R \& D$ collaboration after their participation. Already within the same year as participation the probability of entering R\&D

collaboration increases by 95 percent. The year after participating in an innovation network the probability of entering $R \& D$ collaboration is

${ }^{6}$ Cf. The Danish Agency for Science, Technology and Innovation, 2011 almost 300 percent higher than other similar companies not partipating in innovation networks .

It not was possible to obtain a satisfactory number of observations in the third, fourth and fifth year after participation. Therefore there are no results of these models.

Table 5.2: Level of R\&D collaboration after participating in an innovation network

\begin{tabular}{|lc|}
\hline $\begin{array}{l}\text { Year after participating in } \\
\text { Innovation Networks }\end{array}$ & $\begin{array}{c}\text { Increased probability of being } \\
\text { innovative }\end{array}$ \\
\hline The same year & $0.9459^{* * *}$ \\
\hline Year 1 after participation & $2.9978^{* * *}$ \\
\hline Year 2 after participation & $3.8494^{* * *}$ \\
\hline Year 3 after participation & N/A \\
\hline Year 4 after participation & N/A \\
\hline Year 5 after participation & N/A \\
\hline
\end{tabular}

Source: DAMVAD, 2011.

Note: The significance is marked with asterisk : ${ }^{* *}=1$ pct.-level, ${ }^{* *}=5$ pct.-level and ${ }^{*}=10$ pct.level.

$\mathrm{N}: 2,350$

\section{Interpreting the results}

The results of the impact assessment show that participation in an innovation network significantly increases the probability of having $R \& D$ collaboration. There can be several explanations to the results:

Increased network externalities as explained under the analysis of better use of other R\&D and innovation programmes the ability to enter joined $R \& D$ and innovation projects is not straight forward. It requires absorption capacity and a certain level of intern knowledge within the company. A lot of companies, particularly smaller 
companies, do not possess these capacities and as such then innovation network assist the companies in overcoming this drawback. The same explanation can be implied to why innovation network should increase the probability of entering and having $R \& D$ collaboration.

\section{Providing the opportunity to identify collaboration partners and to} launch projects is one of the main objectives for the innovation networks. One of the activities in the networks is "bridge builder" function where participating companies in innovation networks receive assistance in order to identify suitable partner to a $R \& D$ or innovation project. Further the access to a comprehensive network of researchers, technological service providers and private companies implies an increase in R\&D collaboration. Finally the fact that there is $R \& D$ collaboration projects within the different innovation network yields itself a higher level of $R \& D$ collaboration.

\subsection{Better use of other R\&D and innovation programmes}

It is possible to analyze whether participation in innovation networks leads to an increased the use of national and international programs. By establishing a control group of companies that have not yet participated in innovation networks and over time investigate their use of other national and international programs.

Participation in other programs is identified through the DAMVAD Database on R\&D and innovation programs. The database is build on information regarding company participation in national programs, e.g. Innovation Consortia or the program for strategic research and international programs such as the EU framework programs.

The use of the database provides us with the possibility to answer whether participation in Innovation Networks leads to increased use of the innovation system. If so Innovation Networks plays a significant role in catalyzing participation in other more formal $R \& D$ and innovation programs both nationally and internationally.

Tabel 5.3 presents the results of the analysis on whether participation in Innovation Networks increases the use of other R\&D and innovation programs compared to similar companies that have not participated in Innovation Networks. The results represent the outcome of a logistic regression modelling the probability of entering other programs when participating in Innovation Network. The logistic model also allows for including other predictor variables that will affect the probability of entering R\&D or innovation programs ${ }^{7}$. In all 6 models are estimated ranging from effect the same year to participation 5 years after entering Innovation Networks.

\section{There is a better use of other programmes}

Tabel 5.3 shows that compared to other similar companies Innovation Networks participating companies in innovation networks experience a significantly higher probability of participating in other programmes two and five years after participation in an innovation network.

Two years after participating in an innovation network participant have an increased probability by 141 percent of participating in other programmes compared to other similar companies. Five years after participating in an innovation network this have increased to 215 percent. Eventhough the results are general positive and shows an increased probability of participating in other programmes the significance differs throughout the period.

\footnotetext{
${ }^{7}$ In the report "The Impact on Company Growth of Collaboration with Research Institutions", The Danish Agency for Science, Technology and Innovation, 2011 it is shown that factors such as sector, firm size and employees with tertiary education have a high impact on the probability of $R \& D$ collaboration.
} 
Table 5.3: Better use of other programmes

\begin{tabular}{|lc|}
\hline $\begin{array}{l}\text { Year after participating in } \\
\text { Innovation Networks }\end{array}$ & $\begin{array}{c}\text { Increased probability of } \\
\text { participation in other programmes }\end{array}$ \\
\hline The same year & 0.1704 \\
\hline Year $\mathbf{1}$ after participation & 0.5237 \\
\hline Year $\mathbf{2}$ after participation & $1.4087^{\star *}$ \\
\hline Year $\mathbf{3}$ after participation & 0.8043 \\
\hline Year $\mathbf{4}$ after participation & 0.5121 \\
\hline Year $\mathbf{5}$ after participation & $2.1499^{\star * *}$ \\
\hline
\end{tabular}

Source: DAMVAD, 2011.

Note: The significance is marked with asterisk : ${ }^{* *}=1$ pct.-level, ${ }^{* *}=5$ pct.-level and ${ }^{*}=10$ pct.level.

$\mathrm{N}: 6,066$

\section{Interpreting results}

The results of the impact assessment show that participation in the Innovation Network programme increase the probability of participating in other $R \& D$ and innovation programmes. There can several explanations to this result:

\section{Providing participating companies in innovation networks with}

overview and contacts One of the cornerstones of the Innovation Networks is their ability to provide participating companies in innovation networks with an overview of and contact to other R\&D and innovation programmes. Further they provide the participating companies in innovation networks with access to a comprehensive network of researchers from universities, technological service providers as well as other private companies, which all potentially have experience with other parts of the public research and innovation promotion system. As such they will be able to direct the participant to other relevant programmes.

25
Turning inexperienced users into experts While other R\&D and innovation programmes often attracts the elite of research and knowledge intensive companies, the innovation networks also is relevant for more inexperienced companies. The Innovation Network helps inexperienced users of the research and innovation promotion system to become more familiar with the system.

It is argued that participation in knowledge intensive and advanced $R \& D$ and innovation projects requires an initial knowledge base among participating companies in innovation networks. Companies participating in joined R\&D collaboration have to provide knowledge and other inputs to the project. Otherwise they will be excluded from the project and receive a bad reputation and seen as free-riders, cf. Robertson and Gatingnon (1998). Innovation networks assist and help companies to establish the right initial knowledge base that will help them be successful in other programmes.

Further the absorption capacity of a company has a huge impact on their ability to gain from the knowledge provided by others in R\&D and innovation projects. Cohen and Levinthal (1990) argues that the absorption capacity is of greatest importance to discover, understand and embed new knowledge. Further the absorption capacity will be of great importance to forward exploit the knowledge gained from joined R\&D and innovation projects, cf. Kastelli (2004) and Vinding (2002).

Other studies have shown that it largely is larger companies that possess the basis capabilities and absorption capacity that enables them to gain from joined R\&D and innovation. That is often referred to as one of the main reasons to why larger companies tend to be overrepresented in joined R\&D and innovation programmes as well as when focusing on R\&D collaboration, e.g. 40 percent of the participating companies in innovation networks in the Programme for Strategic Research have more than 250 employees and 27 pct. in Innovation Consortia. While in the Innovation Networks it is just 11 pct. that have more than 250 employees. 
As such the innovation network programme is playing a central role in enabling inexperienced and smaller companies without the basic

knowledge skills into the public research and innovation promotion

system and thus is assisting companies in moving up the "knowledge

ladder". 


\section{Possible economic impacts}

In general, the analyses of the behavioural changes of the companies indicate that they change their behaviour as a result of their participation in the innovation networks. On the other hand, it takes a number of years before these behavioural changes affect their economic performance. For instance, Rouvinen (2002) points out that investments in R\&D do not improve the general performance until 3 to 5 years after the initial investment. When the investment is eventually developed into new products, more efficient processes or new services that increase earnings, this will, however, affect the general performance. The available data does not include time series extensive enough for calculating the exact economic effects at this time. In a few years, we expect to able to do just that.

This chapter looks at the possible economic effects of participating in innovation networks. The previous chapter focussed on the change in behaviour of the participating companies in innovation networks. The results showed that,

- Participating companies are far more likely to become innovative after having participated in an innovation network than other, similar companies are.

- Participating companies are far more likely to enter into R\&D collaborations after having participated in an innovation network than other, similar companies are.

These behavioural changes indicate that the companies will experience learning externalities. Autio m.fl. (2008) point to this as a so-called second order effects of participating in public innovation programs. These effects primarily allude to the learning capabilities enhanced by the public intervention that boost knowledge creation and relations among agents in the innovation system.

\subsection{Possible impact of increased innovation}

The results from the previous chapter show that participating companies in the innovation networks increase their probability of being innovative by a factor of 4.5 compared to a control group of companies with similar characteristics. This means that for each 10 companies in the control group that turn innovative, 45 companies in the innovation networks will turn innovative.

Innovation leads to the creation of new products, processes and services in businesses, increasing earnings and at the same time raising the level of knowledge. They will thus make the innovative companies more competitive in the long run, benefiting productivity and growth.

Innovation networks are a result of a wish to give the innovation effort of Danish companies a boost. The result of the analysis of the changed behavior of the participating companies in innovation networks indicated a far greater likelihood of becoming innovative after having participated in an innovation network.

A recent Danish study ${ }^{8}$ shows substantial effects of investment in innovation. Additional investments in innovation activities yield a return on investment of an average of 30 percent based on calculation of the impact that innovation has on labour productivity. Labour productivity is a measure of the average value created by a business per labour year performed. Growing labour productivity means that businesses are improving the size of their income relative to their expenses and thus becoming more competitive.

\footnotetext{
${ }^{8}$ The Impact of Business R\&D and Innovation on Productivity in Denmark,
} 
The study is the most comprehensive conducted in Denmark covering 2,694 companies in the years from 1997 to 2005. Furthermore, the analysis focuses on the solidity of the results and shows that the effect does not differ over time. The result is therefore considered solid.

Furthermore, the econometric model used controls for intermediate variables that otherwise could explain growth in labour productivity.

This means that an increasing the number of innovative companies is expected to have a significant economical impact.

\subsection{Possible impact of increased R\&D collaboration}

The results from the previous chapter showed that participating companies in the innovation networks increase their probability of entering R\&D collaborations by a factor of 4 compared to a control group of companies with similar characteristics. This means that for each 10 companies in the control group that enter R\&D collaborations, 40 companies in the innovation networks will enter R\&D collaboration.

$R \& D$ collaboration has many potential advantages. On a theoretical level, companies can gain from $R \& D$ collaborations in many different ways:

- An overall better ability to absorb and translate new knowledge and technology.

- Faster and easier access to knowledge and technology.

- Economies of scale, which is especially likely to be the case among research-intensive companies.

- Cost minimization in research and innovation projects.

- Reducing the financial risks associated with long-term research investments.

- Access to a wider knowledge and understanding of the latest international research trends and research results
- Strengthening the skills and knowledge through collaboration with researchers

- Strategic outsourcing of research to public research institutions to focus more on its core research activities

A recent Danish study has tested if $R \& D$ collaborations with research institutions result in subsequently higher labour productivity growth. The analysis shows that the companies with $R \& D$ collaborations have a significantly higher growth in labour productivity in each of the years after the collaboration compared to other, very similar companies. The analysis finds an increased annual value added per employee of 9 percent.

The effect is biggest in the first two years after collaboration, as indicated by a significantly higher value added growth per employee compared to companies who have not engaged in collaboration but have the same probability of engaging in this kind of collaboration.

This means that an increasing the number of companies with R\&D collaboration is expected to have a significant economic impact. 


\section{References}

Autio m.fl. (2008), First and Second-order Additionality and Learning Outcomes in Collaborative R\&D Programmes, Research Policy, Vol 37, Issue 1, pages 59-76.

DAMVAD (2011), Økonomiske effekter af erhvervssamarbejde om forskning, udvikling og innovation for the Danish Agency For Science, Technology and Innovation (DASTI), to be published 2011.

DAMVAD (2010), Produktivitetseffekter af erhvervslivets forskning, udvikling og innovation for the Danish Agency For Science, Technology and Innovation (DASTI), ISBN: 978879237249 9, 2010,

Kastelli m.fl. (2004), "Cooperative R\&D as a means for knowledge creation", International Journal of Technology Management, Vol. 27, Number 8, pages 712-30.

Robertson and Gatingnon (1998), "Technology development mode: a transaction cost conceptualization", Strategic Management burnal, Vol. 19, pages 515-31.

Rouvinen (2002), The Existence of R\&D Spillovers: A Cost Function Estimation With Random Coefficients, Economics of Innovation and New Technology, Taylor and Francis Journals, Vol. 11(6), pages 525541.

Vinding (2002), "Absorptive capacity and innovative performance: A human capital approach. Kapitel $7 \mathrm{i}$ Interorganisational Diffusion and Transformation of Knowledge in the Process of Product Innovation, Institut for Erhvervsstudier, Ålborg Universitet 


\section{Appendix 1: Impact study methodology}

This analysis focuses on two different types of impacts of participating in innovation networks:

- Behavioural effects

- Economic impacts

Firstly, this section will present the methodology behind the behavioural impact study. Secondly, it will describe the method used when conducting the economic impacts study.

\section{Estimating the behavioural impact}

The economic impact of participation in innovation networks has been carried out from two different perspectives,

1. A general perspective that attempts to identify the overall participation effect by using the full sample of participating companies in innovation networks disregarding the variation in participation type.

2. A perspective that subdivides participation according to participation type and conducts the impact analysis for each type separately.

For each of the two perspectives, we use a matching approach to estimate the causal effect of participation in innovation networks. This approach matches each participant with a similar non-participant, hereby simulating the counterfactual situation.

The counterfactual situation describes the performance paths participating companies would have followed had they not participated in innovation networks. Clearly it is not possible to observe the participating companies' outcome with and without treatment. We must therefore find a proper substitute for the outcome of participating companies had they not participated.

Assuming that the average outcome of the population of nonparticipating companies is a valid approximation for the counterfactual situation is, however, not a viable solution as participating companies in innovation networks and non-participating companies may differ in the absence of treatment. This selection problem arises because participating companies in innovation networks may be more likely to participate and possibly more likely to benefit from participation.

To circumvent the challenges from selection bias we employ a certain matching technique which identifies non-participating companies that are similar to participating companies in innovation networks given several company specific characteristics.

\section{Matching approach}

This paper uses a particular matching approach called propensity score matching which for all companies involves the estimation of the probability of participating in innovation networks based on observed relevant company specific characteristics. For the specific perspective we model the probability of participation in each of the specific participation types based on a set of observed characteristics.

The probability of participation is estimated using a logit model, which relates the probability of being treated with several company specific characteristics. Thus, the logit model estimates the following conditional probability:

\section{Prob(treatment|X)}


where treatment is a variable that takes the value one in the event of participation and zero otherwise and where $X$ represents a vector of covariates consisting of:
1. Industry
2. Company size
3. Exports
4. Educational background of employees
5. Previous performance
6. R\&D activities
7. Research collaboration

The probabilities are estimated based on five different industries, three different size levels, and five different educational levels.

Industries are subdivided as:

- Low tech manufacturing

- High tech manufacturing

- Wholesale and retail trade

- Knowledge-intensive business services

- Other

Company size is subdivided as:

- 1 to 50 full time equivalent

- 50 to 250 full time equivalent

- Larger than 250 full time equivalent

Educational background of employees is subdivided as:

- Unskilled
- Skilled

- Short education

- Further education

- Higher education and research education

The predicted probability from the logit model is interpreted as the propensity score and therefore constitutes the specified probability of participating based on company specific characteristics.

Participating companies in innovation networks are matched with nonparticipating companies according to a matching algorithm which for each treated unit identifies companies in the population of nonparticipating companies with identical or similar propensity score. This matching algorithm is called Nearest Neighbour matching ${ }^{9}$.

In order to increase the estimation precision, the Nearest Neighbour matching algorithm is augmented so that ten control units are identified and selected for each participant according to the propensity scores. In other words, this matching algorithm picks for each participant those ten non-participating companies that come closest in terms of propensity score.

It is important to consider the quality of the matching, which can be done by testing whether there is additional explanatory power stored in the covariates considering businesses' treatment status after the matching procedure has been carried out. In other words, it has been tested whether there are any observed systematic differences between participating companies in innovation networks and the control group consisting of the matched non-participating companies.

${ }^{9}$ Other matching algorithmS such as the calliper algorithm has been implemented although not resulting in any significant differences regarding the outcome of the matching model compared to the implementation of the nearest neighbour algorithm. 
For each matching procedure performed in this analysis we have carried out a test of the existence of systematic differences between the treatment group and the control group. We are able to reject the presence of such differences, which indicates that the matching procedure throughout the analysis results in a proper balance between participating companies in innovation networks and the selected nonparticipating companies.

The methodology encounters the possibility of selection bias. By establishing the control group from a certain number of explainable factors the control group will have the same probability to participate in the innovation network programme. As such the control group are not randomized but defined especially to match the participating companies. As such they should have the same requisite to enter the programme, to become innovative and to engage in $R \& D$ collaboration.

With this result in hand we are able to interpret any differences in outcomes between the well selected and adequate control group and of participating companies in innovation networks as the causal effect of participating in innovation network.

The table below presents the number of participant by participation type.

Table A.1: Amount of observations according to participation type ${ }^{10}$

\begin{tabular}{|l|c|}
\hline General model & $\begin{array}{c}\text { Number of participating companies in } \\
\text { innovation networks }\end{array}$ \\
\hline Participation type & 1,225 \\
\hline Seminar & 1,225 \\
\hline Matchmaking & 199 \\
\hline Counselling & 148 \\
\hline Projects & 148 \\
\hline
\end{tabular}

${ }^{10}$ Only participations before 2008 are included in the analysis since Statistics Denmark holds no information on companies' performance hereafter.

\section{Performance criteria}

The presence of extreme observations may distort the participation effect and reduce the estimation precession. Data can contain extreme values due to the occurrence of measurement errors or due to mergers and split offs of businesses. Such extreme observations can have a disproportionately large impact on the analysis. Another example is young companies that carry out grand investment projects that affect the company's productivity per full time equivalent for a while. Such companies can experience extreme fluctuations in performance.

To avoid the distorting impact of outliers this paper implements certain performance criteria, which serve as thresholds for which outliers are corrected. In the research literature it is common to remove companies that experience a tripling or a halving in performance between two successive years ${ }^{11}$. This methodology has been implemented throughout the analysis

In order to minimise the impact of outliers and to reduce the variance of the estimator, the 5 percent best and worst performances for each year for participating companies in innovation networks and non-

participating companies are removed from the sample. This correction is implemented to secure a high degree of solidity and reliability of the estimated participation effect.

\footnotetext{
${ }^{11}$ See e.g. Mairesse, Jacques and Hall, Bronwyn Hughes, 1995, "Exploring the Relationship Between R\&D and Productivity in French Manufacturing Firms".
} 


\section{Appendix 2: Data}

The report is based on microeconomic data, primarily from corporate financial accounts and information on research and development activities at corporate level. This section contains a detailed description of the data used in the analysis. The period covered is 2003-2008 unless otherwise stated.

The data was obtained from the following sources:

- Information on the participating companies in the Danish Innovation policy program of Innovation Network (In Danish: "Innovationsnetværk").

- Statistics on Research, Development and Innovation in the Danish Business Sector.

- General enterprise statistics.

- DAMVAD Database on Knowledge Collaboration - a database covering participating companies in major R\&D and innovation programs both nationally and internationally.

Information on the participating companies in the Danish Innovation policy program of Innovation Network was provided by The Danish Agency of Science, Technology and Innovation. These data enable us to identify and characterize the companies participating in Innovation Network. Furthermore, they contain information concerning the time and character of participation.
The Statistics on Research, Development and Innovation $(R D I)^{12}$ in the Danish Business Sector contains detailed information on the expenses and resources allocated to research, development and innovation in Danish businesses. Furthermore, it describes the framework for innovation in Denmark. Data are survey-based, which facilitates comparisons over time. The survey is conducted by Statistics Denmark in accordance with OECD's guidelines for R\&D and innovation statistics $^{13}$.

The purpose of General enterprise statistics is to give a coherent and consistent description of Danish business conditions through economic, employment, and accounting figures at enterprise level. All companies subject to registration according to Danish law are included. The information on economic, employment, and accounting figures is collected every year, which makes it possible to present a detailed set of panel data where key economic variables and company characteristics are monitored over time. This analysis uses data from the General enterprise statistics covering the period from 2001 to 2008.

Finally, DAMVAD Database on Knowledge Collaboration covers projects in all major research and innovation programs, including Innovation Consortia, The Program for Strategic Research, $4^{\text {th }}-7^{\text {th }}$ Framework Program. Overall, the database contains more than 3,800 projects and includes almost 7,800 Danish companies (approx. 2,200 unique companies). The database constitutes an unparalleled source for analysing the extent and nature of the interactions between companies and knowledge institutions in Denmark and their

\footnotetext{
${ }^{12}$ In the years 2004 and 2006 the data were collected as part of the Community Innovation Survey.

${ }^{13}$ For R\&D statistics the data collection follows the Frascati Manual while the innovation statistics were collected in accordance with the Oslo Manual.
} 
participation in the national as well as the international innovation system.

The information on participation in innovation networks contains 6,006 observations. After initial quality assurance and data cleaning, the number of observations falls to 4,664 . This is primarily due to foreign and public companies not being included in the analysis and therefore deleted.

A number of companies appear several times in the same network. This is dealt with by keeping the observation with the highest ranked activity and deleting the others. The final list of participating companies in innovation networks thus ends with 4,021 observations. It is noted that the same company may participate in more than one network. There are 3,388 unique companies in the data set. The distribution of participating companies in innovation networks by network is shown in the table below.

\section{Table A.2. Participating companies in innovation networks by network}

\begin{tabular}{|lr|}
\hline Network & Participating companies in innovation networks \\
\hline A-netværk & 383 \\
\hline AluCluster & 279 \\
\hline Animation HUB & 43 \\
\hline Apex & 206 \\
\hline Bio-netværk & 108 \\
\hline Biomasse & 279 \\
\hline CISS & 354 \\
\hline CSDR & 46 \\
\hline CSI & 37 \\
\hline Center for Sundhedsteknologi & 31 \\
\hline Danvifo & 52 \\
\hline InfinIT & 265 \\
\hline Knowledgelab & 57 \\
\hline Livsstil B\&B & 345 \\
\hline NFBi & 252 \\
\hline NIK-VE & 72 \\
\hline OC DK & 358 \\
\hline
\end{tabular}

\begin{tabular}{|lr|}
\hline PlastNet & 113 \\
\hline SUPPLYNET & 123 \\
\hline Seedland & 18 \\
\hline VE-Net & 184 \\
\hline VIFU/Regionalt Teknologicenter & 311 \\
\hline SundhedsITnet & 105 \\
\hline All & $\mathbf{4 , 0 2 1}$ \\
\hline
\end{tabular}

Source: DAMVAD 2011 based on participation list for innovation networks. 


\section{Appendix 3: The Danish Innovation Network}

\section{Danish Innovation Networks and clusters}

\section{AluCluster - Knowledge and technology centre for aluminium}

Contact: Michael Nedergaard - tel:+ 457473 3040, e-mail: mn@alucluster.com

AluCluster, a centre within practical utilisation of aluminium, offers a wide range of competences within the aluminium area. AluCluster's objective is to create value for the customer through overall solutions.

AluCluster's mission is to meet the need for highly qualified consultancy now and in the future within practical utilisation of aluminium and thereby become the preferred partner in the field of consultancy and development of aluminium solutions.

(nww alucluster.--

www. alucluster.com

\section{Animation Hub}

Contact: Viggo Johannes Jensen - tel:+ 452850 9864, e-mail: vjj@animwork.dk

Animation Hub is a cluster experimenting with animation in the context of development and communication. Based on the competences within animation, such as generating new ideas, dramaturgy, cinematography and simulation, the cluster wishes to help companies find new ways of understanding, accepting and getting involved in innovation processes, developing new concepts, marketing as well as learning, guiding and interaction design.

'www.animationhub.dk

\section{Danish Sound Technology Network}

Contact: Jan Larsen - tel: +: 452243 0025, e-mail: j|@imm.dtu.dk

Danish Sound Technology Network embraces individuals, organizations and businesses involved with sound technology. They will create a new space for innovation, collaboration and dissemination of knowledge.

The vision of the network is that Denmark is a leading country with regard to sound technology in terms of knowledge, research and education. Danish Sound Technology will be the epitome of high quality in products and services, as well as in physical rooms and social contexts.

iwww. Iydtèknologi.dk

\section{FoodNetwork}

Contact: Britt Sandvad - tel: + 459612 7624, e-mail: bs@vifu.net

FoodNetwork is an extensive network which includes a large number of Danish universities, research institutions, Approved Technological Service Institutions (GTS), innovation and development parks as well as technical and vocational schools. The aim of the network is to create growth within the food industry through networks, projects and activities. It is also to be the link that ensures visibility of the relevant partners within the food industry and to support and facilitate existing and new clusters.

iwww.foodnetwork.dik 


\section{Biopeople - Innovation Network for Biotech}

Contact: Per Spindler - tel: +45 2875 6572, e-mail: per@biopeople.dk

Biopeople embraces universities, research organizations, and hospitals, the Danish Medicines Agency, industry associations as well as pharma, medtech, medical device, food and biotech companies.

\section{'www.biopeople.dk}

\section{Infinit - The Danish ICT Innovation network}

Manager of network Aalborg: Rikke Uhrenholt - tel: + 459940 7220, email: aalborg@infinit.dk

Manager of network Copenhagen: Rikke Koch -ph: + 452126 8724, email: kbh@infinit.dk

Infinit is a Danish network for innovative utilization of IT. Its goal is to convert the infinite possibilities that technology offers into concrete collaborations between research and industry.

\section{'www.infinit.dk}

\section{InnoBYG - Innovation Network for Energy efficient and Sustainable} Construction

Contact: Henriette Hall-Andersen - tel: +45 7220 2241, e-mail: hha@teknologisk.dk

The construction industry's new network InnoBYG will facilitate sustainable and energy efficient development in the construction industry from 2010-2014. The focus of the network will be on development projects, knowledge sharing and dissemination and matchmaking across the industry and between companies and knowledge institutions/universities. www.innobyg. dk

\section{The Innovation network for Environmental Technology}

Contact: Jørn Rasmussen - tel:+ 454516 9200, e-mail: jar@dhigroup.com

The Innovation Network for Environmental Technology, Inno-mt, was established in December 2010. The focus is to bring the sectors' soil, water, air and waste together in order to turn them into innovative new products and services across the four sectors.

www.inno-míd

\section{InViO - Innovation network for knowledge-based experience economy}

Contact: Jens F. Jensen - tel:+ 459940 9028, e-mail: jensf@hum.aau.dk

The objective of Innovation network for knowledge-based experience economy is to strengthen knowledge sharing, knowledge

development, and cooperation between businesses and institutions of knowledge relating to innovation and research within the field of experience economy. In this way, the innovation capacity of the businesses is reinforced so that knowledge- and experience-based growth within the industry will be generated.

iwww. invio-net.dk' 


\section{Innovation Network for Biomass}

Contact: Michael Støckler - tel: +: 458999 2504, ms@agropark.dk

The purpose of the Innovation Network for Biomass is to facilitate development within production, handling, and processing of biomass with the goal of better utilization for energy purposes. Its members are individuals and companies involved in the field of biomass, agricultural waste, and manure. The network has an international scope and welcomes both Danish and international members from private companies, research institutions, authorities, etc.

iwww.inbiom. dk

\section{Innovation Network for Danish Lighting}

Contact: Lene Hartmeyer -ph. +: 454717 1800, e-mail: info@dansklys.dk

The object of the Innovation Network for Danish Lighting is to promote the use of good and appropriate lighting and to advance knowledge and information on the improvement of the lighted environment to the benefit of society.

iwww.dansklys.dk

\section{The Innovation network for Market, Communication and Consumption}

Contact: Per Østergaard -ph. + 456550 3235, e-mail: poe@sam.sdu.dk

The network embraces a broad range of core competences that are essential to understand future markets and consumers. Researchers from a classic marketing tradition collaborate with researchers from the humanities, arts, and design. This combination is not common in a Danish context, but crucial in a market where symbolic and emotional dimensions of products are becoming more and more important. The participating researchers come from The University of Southern Denmark, Aalborg University, Aarhus School of Business - Aarhus University, Copenhagen Business School, and Kolding School of Design. iwww.imkf.dk

\section{Service Platform - Service Cluster Denmark}

Contact: Mette Abrahamsen - tel: + 452311 3719, e-mail: ma@dea.nu

The vision for Service Cluster Denmark is to contribute to growth, innovation and competitiveness among service businesses in Denmark. Service Cluster Denmark aims to create new possibilities for cooperation between businesses and knowledge institutions, to strengthen research and innovation in businesses and to incorporate international knowledge and ideas by involving businesses, research institutions and networks outside Denmark.

iwww.serviceplatform.dk' 


\section{Innonet Lifestyle - Interior \& Clothing}

Contact: Betina Simonsen - tel: + 45961662 00, e-mail:

betina@moebelcenter.dk

Innonet Lifestyle - Interior \& Clothing is an innovation Network under the ministry for science, technology and development (STD). The Network's purpose is to promote growth and innovation in the industry of home and fashion by identifying, communicating and embedding new knowledge. The purpose is also to build bridges between companies and institutions of research and knowledge.

iwww.innonetlifestyle.com

\section{Plastic and Polymer Network}

Contact: Dorte Bælum - tel: + 4536973600 , e-mail:

dwb@plastcenter.dk

The cluster consists of a number of companies with an interest in plastic and polymer materials. The aim of the cluster is to increase the awareness of the materials, promote and innovate the use of the materials within and across sectors.

iwww.plastnet.dk

\section{No Age - innovative solutions for elderly people}

Contact: Gunhild Garsdal, tel:+ 453010 8080, e-mail: gg@vhhr.dk No Age aims to make the older people of Denmark more resourceful by supporting their resources and making them capable of taking care of themselves. Companies, leading research institutions,

municipalities, hospitals and organizations are part of No Age's work to develop innovative solutions within health, prevention, nursing,

treatment, etc,

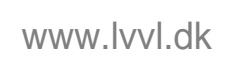

\section{Offshore Center Denmark}

Contact: Peter Blach - tel: + 453697 3670, e-mail:

pb@offshorecenter.dk

Offshore Center Danmark is the official national competence and innovation center for the Danish offshore industry. On behalf of its +210 member companies and institutions Offshore Center Danmark push development with the aim of growth within the Danish offshore industry.

iwww.offshorecenter.dk

\section{RoboCluster}

Contact: Bjarke Nielsen - tel: + 452119 4797, e-mail:

bjarke.nielsen@robocluster.dk

RoboCluster is a Danish innovation network for robotics and automation. The object is to maintain and further expand the robotics sector in Denmark by generating and ensuring optimal conditions for innovation in new as well as existing enterprises and set robotics into action in fields as hospitals, farming, industry, play and education. This is done by initiating technological projects between suppliers, producers, users, universities and knowledge institutions in the field of robotics and automation.

iwww.robocluster.dis 


\section{The Transport Innovation Network - TINV}

Contact: Steen Sabinsky - tel: + 452966 2408, e-mail: ssa@maritimecenter.dk

The Transport Innovation Network (TINV) is a national, cross disciplinary network aimed at the Danish Transport sector. The primary objectives of TINV are to create synergy, encourage matchmaking and generate research and development projects between stakeholders in the transport sector and research and educational institutions, as well as related sectors such as energy and infrastructure.

iwww.tinv.dk'

\section{UNIC - Use of New technologies in Innovative solutions for Chronic} patients

Contact: Dorthe Kjær Pedersen - tel: + 452498 4155, e-mail:

dorthe.pedersen@robocluster.dk

The number of chronically sick people is increasing, and consequently the necessity of treatment and nursing for the chronically sick.

Through development of technological and innovative solutions UNIC aims at reducing the number of hospitalizations, increasing the number of chronically sick people in jobs, more people being able to care for themselves, etc.

iwww.partnerskabetunik.dik

\section{VE-Net - Renewable Energy Innovation Network}

Contact: Grete Bech Nielsen - tel: + 457220 1113, e-mail: gbn@teknologisk.dk

VE-Net (Renewable Energy Network) is an innovative network related to energy and funded by the Danish Ministry of Science, Technology and Innovation. The aim of the network is to create collaboration initiatives between companies and research institutes with the purpose of increasing the application of research-based expertise in the business community and to solve high technology matters.

'www.ve-net.eu

\section{Water in Urban Areas}

Contact: Ulrik Hindsberger, tel:+ 457220 2285, e-mail: uhi@teknologisk.dk

The partnership is directed towards the challenge of adapting cities to a changed climate, and thus it operates within the topic of energy, climate and environmental technologies. The partnership will contribute to realising the vision of Denmark as a climatically strong and green winner nation and establish Denmark as the global demonstratorium for viable water technologies, system solutions and integrated water resource administration. The goal is to develop, document and present technologies and planning tools for climatic adaptation of existing urban areas in Europe, USA and Australia, and for development of new, climatically strong cities in countries in financial and institutional transition, such as China.

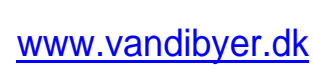

